\title{
A Moral Cleansing Process: How and When Does Unethical Pro-organizational Behavior Increase Prohibitive and Promotive Voice
}

\author{
Ying Wang $^{1} \cdot$ Shufeng Xiao ${ }^{1} \cdot$ Run Ren $^{1}$
}

Received: 2 February 2020 / Accepted: 4 December 2020 / Published online: 8 January 2021

(c) The Author(s), under exclusive licence to Springer Nature B.V. part of Springer Nature 2021

\begin{abstract}
In this study, we draw on moral cleansing theory to investigate the consequence of unethical pro-organizational behavior (UPB) from the perspective of the actors. Specifically, we hypothesize that after conducting UPB, people may feel guilty and tend to cleanse their wrongdoings by providing suggestions or identifying problems at work (i.e., prohibitive and promotive voice). We further hypothesize that the above relationship is moderated by the actor's moral identity symbolization. We conducted three studies, including experiment and surveys, to test our hypotheses. Results of these studies show consistent support to our hypotheses. In particular, individuals reported more felt guilt after conducting UPB, and they tended to compensate with more prohibitive and promotive voice subsequently. In addition, the indirect relationship from UPB acting to both voice behaviors via felt guilt was stronger for people with a high level of moral identity symbolization. Theoretical and practical implications are discussed.
\end{abstract}

Keywords Unethical pro-organizational behavior (UPB) $\cdot$ Moral cleansing theory $\cdot$ Felt guilt $\cdot$ Prohibitive and promotive voice $\cdot$ Moral identity symbolization (MIS)

\section{Introduction}

The striving and prosperity of a company depends on employees' in-role performance, as well as their extra-role efforts (e.g., Bass 1985; Podsakoff et al. 1990; Yukl 1989). Defined as unethical conducts with an intention to benefit the organization, unethical pro-organizational behaviors (UPB), a form of employees' extra-role behavior, widely exist in organizational settings (Umphress et al. 2010). For example, a survey of employed US workers as of May 2006 reported that a third of the staff witnessed unethical conducts at work, while $19 \%$ of them is cheating employees,

Ying Wang and Shufeng Xiao contribute equally to this research.

Run Ren

renr@gsm.pku.edu.cn

Ying Wang

qwang_ying@pku.edu.cn

Shufeng Xiao

xiaoshufeng521@gmail.com

1 Department of Organization and Strategy Management, Guanghua School of Management, Peking University, No. 5 Yiheyuan Road, Haidian District, Beijing 100871, China customers, suppliers, or public for the interest of the organization (Gurchiek 2006). More recently, it was reported that the customer service staffs of a large travel agency in China persuaded their customers not to ask for invoices, in order to help the organization avoiding taxes (ThePaper, June 1st, 2019). Intending to promote the effective functioning of the organization or its members, employees conduct UPB but at the cost of core societal values, mores, laws, or standards of proper conduct, which may leave hidden troubles to the organization and the actors (Umphress et al. 2010; Umphress and Bingham 2011).

Although UPB has caught much attention from researchers (e.g., Chen et al. 2016; Matherne and Litchfield 2012; May et al. 2015; Umphress et al. 2010; Umphress and Bingham 2011; Wang et al. 2019a, b), most of them focus on investigating the antecedence of UPB while neglecting its potential consequences, especially to the actors. Understanding the influence of UPB on the actor is important because people usually value a moral self-image (Monin and Jordan 2009), and want to behave morally (Mazar et al. 2008). Although they may occasionally disengage from their core moral self and engage in unethical behaviors, ethical dissonance may occur afterwards (Barkan et al. 2012). In other words, people who conducted unethical behaviors could 
actually recognize the unethicality of their deeds, which violates their moral self-image (Bonner et al. 2017). In order to restore their moral self, these individuals usually go through a moral cleansing process by engaging in moral behaviors to offset prior bad deeds (Sachdeva et al. 2009).

As people appear to take targeted reparatory actions toward those they wronged or hurt (Cryder et al. 2012), we choose to focus on employees' voice behavior as their moral cleansing choice. On one hand, voice refers to employees' discretional expression of their ideas or concerns about work-related issues to improve the functioning of the organization (Morrison 2011; Van Dyne and LePine 1998). Given the potential benefits to the organization, voice can balance the unethical deeds they performed previously which, though seem to be for the good of the organization, cost the organization in the long run. In addition, voice behavior is about either doing the right to improve processes or stopping the wrong to avoid errors (Liang et al. 2012), we contend that voice behavior may indirectly compensate the stakeholders who were harmed by previous UPB. For example, by suggesting ideas to improve the product, the necessity to hide flaws or exaggerate functions of the product can be accordingly reduced, preventing customers from being furtherly hurt; by voicing against illegal procedures like falsifying vouchers, shareholders may be protected from going broke.

Therefore, in the current research, we follow a moral cleansing perspective (Zhong and Liljenquist 2006) and propose that employees' past UPB may lead to feelings of guilt and consequently encourage their constructive behaviors to wash out their sins. Moreover, we suggest that people with a high moral identity symbolization (MIS), which refers to the degree to which the moral traits are expressed publicly through the person's actions in the world (Aquino and Reed 2002), will have a stronger desire to offset their immoral behavior by making compensations, in the form of voice (i.e., prohibitive and promotive voice). By engaging in reparatory behaviors that can be recognized, these employees can restore their self-image in the eyes of others (Carlsmith and Gross 1969).

The study contributes to the existing literature in the following aspects. First, it advances existing knowledge of UPB by examining psychological and consequently behavioral outcomes of UPB from the perspective of the actors. Current research on UPB primarily focus on its antecedences, and much less is known about its consequences. By introducing a moral cleansing mechanism, we extend our understandings about UPB that although it is conducted in the name of others' good, UPB actors are likely to feel guilty and in turn engage in compensating behaviors, such as prohibitive and promotive voice.

Second, we also contribute to the voice literature by examining the role of felt guilt in predicting prohibitive and promotive voice, answering calls of research on affect and emotion in influencing voice behavior (Morrison 2011). In addition, by examining voice as a choice to cleanse moral debts, we provide evidence for its moral facet.

Third, we also contribute to the moral identity literature by emphasizing the role of its symbolic dimension in strengthening the process of moral cleansing. Although several studies call attention to differentiating the specific roles of moral identity internalization and symbolization (e.g., Gotowiec and van Mastrigt 2019; Jordan et al. 2011; Skarlicki et al. 2008; Winterich et al. 2013), most studies exploring the moderating effects of moral identity theorize the effect of the unidimensional construct but operationalized it with the internalization subscale (e.g., Johnson and Umphress 2019; Skarlicki et al. 2016; Xu and Ma 2016). The current research adds to the moral identity literature by clarifying the role that MIS plays in restoring a public moral self-image via engaging in observable compensating behaviors such as prohibitive and promotive voice.

\section{Theory and Hypotheses Development}

\section{Unethical Pro-organizational Behavior and Felt Guilt}

Essential to the definition of UPB are the dual characteristics that the act is undertaken with the intention to help the organization or its members and yet violates hyper moral standards of the society (Umphress et al. 2010). Besides its harm to the outside stakeholders such as customers and competitors, however, UPB may also exert detrimental influence on the organization in the long run. For example, "destroying incriminating documents to protect the organization may heighten external auditors' suspicions and prompt fines or more negative consequences" (Umphress et al. 2010, p. 770), and exaggerating the functions of the company's products or services may damage the corporate image and reputation (Lee et al. 2019). This is exactly what happened to Pfizer, a pharmaceutical giant company, who was fined $\$ 60$ million dollars to settle charges that the company violated the Foreign Corrupt Practice Act by bribing foreign officials for contracts (CNN.com 2012).

Given these harms and costs, after conducting UPB, people may evoke a state of ethical dissonance and feel bad about themselves (Gollwitzer and Melzer 2012). This is because most individuals value morality in their self-concept and do not want to cause harm to others (Aquino and Reed 2002; Blasi 1993), even though they sometimes are tempted to gain profit from unethical conduct. We argue in the current research that after employees perform UPB, they will experience guilt, or a kind of agitation-based emotion of regretting a wrong action or decision (Ghorbani et al. 2013). 
It should be noted that when Umphress and Bingham (2011) first defined UPB, they emphasized that such behaviors "violate core societal values, mores, laws, or standards of proper conduct" (p. 622), and did not explicitly discuss whether the UPB actors had the awareness of the immorality of their behaviors. However, there are some evidence showing that the UPB actors could actually, more or less, recognize what they have conducted is unethical. For example, Umphress and Bingham (2011) distinguished UPB from "work-related actions involving ... unconscious negligence" (p. 623), and stated that it is possible for the actors to "make inferences based on the possibility for harmful consequences to entities other than the organization" ( $p$. 623). Empirically, Graham et al. (2020) investigated the relationship between perceived ethicality of UPB and the intention to perform UPB. Through three studies, they found that although employees would be more likely to engage in UPB when they perceived UPB to be relatively less unethical, most employees (including the potential UPB actors) did recognize UPB as unethical, with consistently low ratings of perceived ethicality of UPB.

Just as "Eve wanted the apple but knew that she should not eat it" (Bazerman et al. 1998, p. 225), employees conduct UPB while simultaneously recognize the unethicality of such behaviors. As Bazerman et al. (2018) demonstrated, people usually have a "want" self and a "should" self. The "want" self is about affective, hot headed, and short-term goals, while the "should" self is related to rational, cool headed, and long-term goals (Bazerman et al. 1998). In the case of UPB, employees' "want" self may be to gain immediate benefits for the organization, while their "should" self is to be a moral and good citizen (Ruedy et al. 2013). Employees' "want" self takes over at the moment when they conduct UPB (Tenbrunsel et al. 2010), but the "should" self still exists and is unfulfilled. The inconsistency between the "should" self (i.e., to be a moral person) and the unethical actions (i.e., UPB) may lead to a sense of dissonance (Festinger 1957) and result in subsequent negative feelings, such as guilt (Bierbrauer 1992; Bohns and Flynn 2013; Tang et al. 2020; Tracy and Robins 2006).

Taken together, as UPB actors usually have the awareness that their behaviors are unethical and cause harms, violating their "should" self goal to be a moral person, we hypothesize that UPB acting is positively associated with feelings of guilt.

Hypothesis 1 UPB acting is positively related to employees' felt guilt.

\section{UPB, Felt Guilt, and Two Kinds of Voice}

Although people usually want to be perceived as good and honest (Jordan et al. 2011; Shalvi et al. 2015), they sometimes cannot resist to gain benefit from dishonesty or unethical behaviors (Barkan et al. 2012, 2015). After behaving unethically, their morality is damaged, triggering guilta negative moral emotion to be cleansed with compensating moral or worthy actions (e.g., Zhong and Liljenquist 2006). Extant literature has declared the relationship between guilt and multiple subsequent behaviors, such as reducing prejudice (Amodio et al. 2007), apologizing and compensating (Ghorbani et al. 2013), ethical decision-making (Steenhaut and Van Kenhove 2006), disclosure (e.g., tax amnesty disclosure, Dunn et al. 2018), self-punishing (e.g., seeking for experiencing pain, Bastian et al. 2011), and adopting prosocial behaviors (Harth et al. 2013). However, recent research asserted that guilt feelings exert more pronounced effect on targeted actions toward the victims other than broad prosocial behaviors (Cryder et al. 2012). That is, we should simultaneously consider the victims of transgressions when discussing reparatory actions to remove guilt.

In the current study, we focus on voice as one amending action to cleanse guilt triggered by UPB acting. Voice involves discretionary expression of ideas, suggestions, concerns, or opinions about work-related issues with the intent to improve organizational or unit functioning (Morrison 2011). Liang et al. (2012) further developed two kinds of voice behavior: promotive and prohibitive voice. Promotive voice refers to employees' expression of new ideas to improve the status quo, which involves suggesting ways in which the unit or organization can perform better in the future. On the other hand, prohibitive voice focuses on employees' expression of concerns about harmful practices in the organization, which is directed at avoiding failures as it highlights factors that adversely impact work processes (Kakkar et al. 2016; Liang et al. 2012).

We argue that UPB transgressors may adopt prohibitive and promotive voice to cleanse their guilt emotions for two reasons. First, amends can be made to victims of past UPBthe organization and its stakeholders via these two voice behaviors. For the organization, by expressing message to initiate improvement and positive change, voice behavior has been found to bring about multiple benefits. For example, Morrison and Milliken (2000) found that upward voice facilitates effective decision-making and error detection; while many other scholars found that employees' voluntary contributions of ideas and information helped to improve current work processes (Detert and Burris 2007; Dutton and Ashford 1993; Tangirala and Ramanujam 2010).

Moreover, though benefiting the organization, UPB is unethical and violates common moral standards and/or societal values (Umphress and Bingham 2011). This means that some other people may be the victims of their UPB. To cleanse their misconduct and restore morality, employees may compensate by proposing constructive ideas and suggestions to improve the performance of the company (e.g., 
Detert et al. 2013), which ultimately improve the welfare of outside stakeholders. For example, by voicing against immoral issues or ineffective process, prohibitive voice corrects errors and prevents the organization from further wrongdoings, thus protecting the external stakeholders from being hurt in the future (Detert and Burris 2007). Moreover, by voicing about how to help the organization perform better, promotive voice can help the organization improve the quality of their goods, services, sales, and so on (Liang et al. 2012), consequently benefiting clients, customers, and the overall society.

Recent literature has also discussed the moral facet of voice behavior that it may do good to the outside stakeholders. For instance, Wang et al. (2019a, b) found that employees conducted more prohibitive and promotive voice when they felt their organizations were more socially responsible. The reason is that organizations' CSR (i.e., corporate social responsibility) convey to employees that they value welfare of multiple stakeholders (Vlachos et al. 2014). In response, employees of such organizations will also help to promote the welfare of various stakeholders by providing valuable suggestions and pointing out concerns. Moreover, voice is also regarded as an effective moral choice in dealing with dysfunctional leaders (Caldwell and Canuto-Carranco 2010), since speaking out one's concerns fulfills the moral duty of organizational citizens to work for the long-term welfare of the organization and others. This evidence also suggests that voice has moral values. ${ }^{1}$

Second, we argue that felt guilt after conducting UPB may make the actor willing to bear the potential risks entailed by voice. Unlike other constructive behaviors, at the workplace, employees frequently face the choice of whether to speak up or keep silent about important work issues. As it challenges the status quo (Detert and Burris 2007), pointing out problems may lead to potential conflicts between the voicer and the recipient (Lin and Johnson 2015). In other words, implied in the definition of voice is that it entails risk (Liu et al. 2010), and risk may cause feelings of loss and is thus most frequently rebuffed by people (e.g., Tom et al. 2007).

However, as a manifestation of psychological dissonance, the emotion of guilt can be cleansed to a larger extent if the

\footnotetext{
1 We also conducted a separate online survey with 173 employees ( $47 \%$ were male, age at 33 on average, $82.7 \%$ have a college or higher degree, with at least 1e year of work tenure (mean $=3.73, \mathrm{SD}=1.27$ ). We measured their prohibitive and promotive voice (measured by Liang et al. 2012; $\alpha=.89$ and .93); moral identity (measured by the 10-item scale developed by Reed and Aquino 2003; $\alpha=.89$ ); moral voice (measured by Hannah and Avolio 2010; $\alpha=.76$ ); and ethical behavior (measured by Baker et al. 2010; $\alpha=.85$ ). Results showed that prohibitive and promotive voice correlated with moral identity $(r=.40, .36, p<.001)$, moral voice $(r=.40, .31, p<.001)$, and ethical behavior $(r=.15, .19, p<.05)$. This evidence suggests again that voice has a moral facet.
}

actor suffers. For example, research showed people believe that self-inflicted pain help purify sins (Glucklich 2001) and self-punishment help remove feelings of guilt associated with immoral behaviors (Nelissen and Zeelenberg 2009; Tangney et al. 2007). Therefore, perpetrators could seek for pains as the penalty to offset the bad deeds. After they suffer, a justification process emerges for their previous wrongdoings and people can wipe out their feelings of guilt, and cleanse the self to be moral again. As the feelings of guilt grow, their tendency to cleanse will also increase, while the risks associated with voice and the pain it may cause can help with cleansing the feelings of guilt. Therefore, employees who feel guilty after UPB will not fear the potential risk of voice.

Concluding the preceding argument, we hypothesize that,

Hypothesis 2 UPB acting is positively related to the actors' voice behavior, in the form of both (a) prohibitive voice, and (b) promotive voice, through the mediation of felt guilt.

\section{The Moderating Effect of Moral Identity Symbolization (MIS)}

Although high moral cleansing intention is likely to solicit voice behavior following UPB and felt guilt, the extent to which such process may happen could vary among different individuals. Specifically, we focus on individuals' moral identity symbolization as a significant boundary condition.

According to Aquino and Reed (2002, 2003), moral identity is a self-conception organized around a set of moral traits such as honesty, kindness, and helpfulness. People with a strong moral identity see it as an important and central part of their self-identity (Aquino and Reed 2002). Such individuals will strive to maintain consistency between conceptions of their moral self and their moral actions (Younis and Yates 1999) and are therefore more sensitive to ethical dissonance. Moral identity has two dimensions: moral identity internalization (MII), which reflects the degree to which a set of moral traits is central to the self-concept, and moral identity symbolization (MIS), which reflects the degree to which these traits are expressed publicly through the person's actions in the world. Past research has differentiated the roles of these two dimensions mainly in terms of public recognition. In particular, people with a high level of MII tend to act prosocially regardless of whether their acts will be recognized, while people with a high MIS will be more likely to act prosocially when others can witness and/or acknowledge their behaviors (Skarlicki et al. 2008; Winterich et al. 2013). Given that voice behavior is employees' action expressed to others (e.g., supervisor, coworker), we focus on the role of MIS in moderating the relationship between guilt and voice behaviors. 
Extant research suggests that MIS smooths the process of balancing one's moral account. From the moral cleansing perspective, Jordan et al. (2011) found that recalling past immoral behaviors increased the activation of MIS while the level of MII remained stable. The reason is that the recall of past unethical behaviors caused a sense of moral incompleteness, which led participants more eager to self-symbolize their moral identities to others by engaging in compensating behaviors. While from the perspective of moral licensingengaging in unethical behaviors after conduction of moral acts, MIS is found to have similar effects. For example, Ormiston and Wong (2013) found that CEO MIS strengthened the relationship between prior corporate social responsibility acts (CSR) and later corporate social irresponsibility behaviors (CSiR), because "high levels of past CSR should signal to leaders with high MIS that they have met their moral standard of appearing moral to others" (p. 871). In other words, leaders with high MIS will perceive that their prior CSR have bolstered their moral credits. As such, the goal of appearing moral to the public will be less accessible for these leaders, causing them to engage in fewer symbolic moral acts.

Aligned with this stream of research, we argue that employees' MIS strengthens the relationship between felt guilt and two kinds of voice behaviors. Specifically, when MIS is high, employees have a strong desire to show their moral self-image to the public. Consequently, when they feel guilty after conducting UPB, their desire to restore moral self-image may arise and will be more likely to conduct voice behaviors. On the contrary, when employees have low MIS, they will be less likely to engage in voice behaviors even though they feel guilty. This is because they have not shown the public that they value morality in their self-concept, and thus do not need to appear moral to others by engaging in behaviors that can promote their morality. Therefore, we propose the following hypothesis,

Hypothesis 3 Moral identity symbolization (MIS) moderates the relationships between felt guilt and employees' (a) prohibitive voice, and (b) promotive voice. Specifically, the positive relationship is stronger for people with high rather than low MIS.

Taken together, we hypothesize that the strength of the indirect relationship from UPB acting to two kinds of voice behavior via felt guilt also varies, depending on the level of MIS.

Hypothesis 4 Moral identity symbolization (MIS) moderates the indirect relationship between UPB acting and employees' (a) prohibitive voice, and (b) promotive voice via felt guilt, such that the indirect relationship is stronger for those high rather than low in MIS.

\section{Overview of Studies}

We conducted three studies to test our hypotheses. In Study 1A, we applied a scenario-based experiment to test the causal relationship between UPB acting and intention of two kinds of voice behavior, through the mediating role of felt guilt. In Study 1B, we designed a context for the participants to actually conduct or not conduct UPB, and examined whether those conducted UPB would recognize the unethicality of their behavior and feel guilty, then compensate by engaging in voice behavior (e.g., raising suggestions or concerns in terms of team work). In Study 2, we conducted a two-wave field survey with MBA students who had ample working experience. Their actual UPB and two kinds of voice behavior were measured, and we tested both the mediating effects of felt guilt and the moderating effects of MIS.

\section{Study 1 A}

\section{Participants and Procedure}

Participants of this study were 159 part-time MBA students taking Human Resource Management course of a large university in Northern China. Among them, $64.8 \%$ were male, their average age was 32.0 years old $(\mathrm{SD}=3.4)$, and they have an average work tenure of 8.7 years $(\mathrm{SD}=3.2)$. Participation was voluntary and confidentiality was guaranteed. Each participant received a course credit for participating in the study. A link to the questionnaire was sent to their e-mail addresses. After providing their demographic information, participants read a scenario in which they were assumed to conduct either UPB or routine in-role behavior and responded to questions that assessed their felt guilt and their two kinds of voice behavior intention.

\section{Scenarios and Experimental Manipulations}

We created our UPB scenarios based on the three aspects of UPB definition suggested by Umphress et al. (2010): unethical, not formally required, and an intention to benefit the organization. Initial versions of the scenarios were sent to 61 working employees and supervisors in different organizations for feedback and comments. We revised and finalized the scenario based on their feedback.

\section{UPB Acting Versus Non-UPB Acting}

We manipulated UPB acting (Scenario I, $N=83$ ) versus non-UPB acting (Scenario II, $N=76$ ). In both scenarios, participants were told, "You are an HR manager of a large company, and at this time company B is competing with 
your company intensely. Now you need to recruit a finance manager and have received several applications. You accidentally find that candidate A had once pocketed money from the previous employer." Next, in the UPB acting condition (Scenario I), participants read, "For the good of your company, you delete A from the candidate list but strongly recommend A to apply for the same job vacancy in company B, so that candidate A may be company B's problem rather than your company's. Moreover, it may benefit your company in the competition with company B." In this scenario, we purposely emphasized a strong competitor of the company. In such a situation, though the applicant may apply to other firms after the rejection, the HR manager (i.e., the participant) may mislead the applicant who has a salient shortcoming by encouraging him/her to apply for the position of the competitor, with the hope that the competitor may not be lucky to know this applicant's shortcoming. If the applicant is hired by the competitor, he/she may pocket the money from the company again and thus harm the competitor, which then helps the participant's company. So, the behavior in our UPB scenario is unethical, not formally required, and intending to benefit the organization. In the non-UPB acting condition (Scenario II), participants simply read, "Following the company requirement of the vacant position, you delete A from the candidate list."

\section{Measures}

Since our participants for all three studies were Chinese, we prepared the scales in Chinese, following the translation and back-translation procedures recommended by Brislin (1986). Unless otherwise noted, all the items in the three studies were rated on a 7-point Likert scale ( 1 = "Strongly disagree", $7=$ "Strongly agree").

\section{Felt Guilt}

We adapted 12 items from Cohen et al.'s (2011) Guilty and Shame Proneness Scale (GASP) to measure felt guilt in our study. Since the GASP scale was composed of specific contexts and corresponding feeling statements, we revised the items to fit our scenario context. The original scale included 16 items. To keep it more concise, we deleted 4 items that are either highly overlapped with other items or not applicable to the scenario (e.g., "Your home is very messy and unexpected guests knock on your door and invite themselves in. What is the likelihood that you would avoid the guests until they leave?"). Sample items included, "After doing so, I feel unpeaceful in my heart;" and "Although I did so, I know it is not appropriate" (Cronbach's $\alpha=0.95$ ).

\section{Prohibitive and Promotive Voice Intention}

Participants rated the extent to which they would act as stated using Liang et al.'s (2012) scale of prohibitive and promotive voice. This scale includes 10 items measuring prohibitive (5 items, $\alpha=0.91$ ) and promotive voice (5 items, $\alpha=0.95$ ) respectively. Sample items included "In the future work, I will speak up honestly with problems that might cause serious loss to the work unit, even when/though dissenting opinions exist" for prohibitive voice intention; and "In the future work, I will proactively develop and make suggestions for issues that may influence my unit" for promotive voice intention.

\section{Manipulation Check Items}

We composed 5 items to capture if participants could recognize the nature of the behaviors in the scenarios to be UPB or not (i.e., unethical, not formally required, and intended to benefit the organization, Umphress et al. 2010). These five items include, "To be fair, what I have done is unethical;" "Objectively speaking, what I have done is not morally acceptable;" "In essence, my job responsibility does not require me to do so;" "In fact, I was not commanded by my supervisor to do so;" and "I did so with an intention to benefit my organization."

\section{Results}

\section{Manipulation Check}

Prior to testing our hypotheses, we examined whether our manipulation of UPB was effective. ANOVA results show the two scenarios differed in terms of unethicality, discretion, and intention to benefit the organization of the behaviors described. Specifically, for the item "To be fair, what I have done is unethical", scenario I (UPB acting, mean $=5.71, \mathrm{SD}=1.17)$ differed significantly from scenario II (non UPB acting, Mean $=2.34, \mathrm{SD}=1.08$ ), $F(1$, $157)=353.13, p<0.001$; for the item "Objectively speaking, what I have done is not morally acceptable", scenario I (UPB acting, mean $=5.63, \mathrm{SD}=1.26$ ) differed significantly from scenario II (non UPB acting, mean $=2.64, \mathrm{SD}=1.46$ ), $F(1,157)=191.74, p<0.001$; for the item "In essence, my job responsibility does not require me to do so", scenario I (UPB acting, mean $=5.71, \mathrm{SD}=1.59$ ) differed significantly from scenario II (non UPB acting, mean $=3.22, \mathrm{SD}=1.93$ ), $F(1,157)=79.24, p<0.001$; for the item "In fact, I was not commanded by my supervisor to do so", scenario I (UPB acting, mean $=5.48, \mathrm{SD}=1.67$ ) differed significantly from scenario II (non UPB acting, mean $=4.14, \mathrm{SD}=1.82$ ), $F(1$, $157)=23.29, p<0.001$; for the item "I did so with an intention to benefit my organization", scenario I (UPB acting, 
Table 1 Means and standard deviations by condition in Study 1A

\begin{tabular}{lllll}
\hline Condition & UPB & Felt guilt & $\begin{array}{l}\text { Prohibitive } \\
\text { voice inten- } \\
\text { tion }\end{array}$ & $\begin{array}{l}\text { Promotive } \\
\text { voice inten- } \\
\text { tion }\end{array}$ \\
\hline $\begin{array}{l}\text { Scenario } \\
\text { I (UPB }\end{array}$ & $5.56(0.93)$ & $5.09(1.23)$ & $5.55(1.00)$ & $5.80(1.09)$ \\
$\begin{array}{l}\text { acting) } \\
N=83\end{array}$ & & & & \\
$\begin{array}{l}\text { Scenario II } \\
\text { (non-UPB }\end{array}$ & $3.41(0.97)$ & $3.21(1.19)$ & $5.21(1.09)$ & $5.53(1.13)$ \\
$\begin{array}{l}\text { acting) } \\
N=76\end{array}$ & & & & \\
\hline
\end{tabular}

Standard deviations are in parentheses

mean $=5.33, \mathrm{SD}=1.19)$ differed significantly from scenario II (non UPB acting, mean $=4.67, \mathrm{SD}=1.38$ ), $F(1$, $157)=10.29, p<0.01$. Furthermore, we averaged the five items to form an overall measure of UPB acting manipulation $(\alpha=0.72)$, and results show a significantly higher score of UPB acting (mean $=5.56, \mathrm{SD}=0.93$ ) in scenario I than in scenario II (mean $=3.41, \mathrm{SD}=0.97), F(1,157)=203.72$, $p<0.001$. The above results indicate that our manipulation of UPB acting vs. non-UPB acting is successful.

\section{Tests of the Hypotheses}

Table 1 shows the means and standard deviations for each condition.

A multivariate analysis of variance (MANOVA) show the expected main effects of UPB acting on felt guilt $[F(1$, $157)=96.12, p<0.001]$. Participants in UPB acting condition felt more guilt (mean $=5.09, \mathrm{SD}=1.23$ ) than those in non-UPB acting condition (mean $=3.21, \mathrm{SD}=1.19$ ), thus supporting Hypothesis 1.

MANOVA analyses also show that participants' prohibitive voice intention is higher in UPB acting (mean $=5.55$, $\mathrm{SD}=1.00$ ), than in non-UPB acting condition [mean $=5.21$, $\mathrm{SD}=1.09 ; F(1,157)=4.26, p<0.05]$, but they do not differ in terms of promotive voice intention $[F(1,157)=2.48, n . s$. $]$. We then conducted multivariate regressions to test Hypotheses $2 \mathrm{a}$ and $2 \mathrm{~b}$. Results in Table 2 show that felt guilt has a significant effect on prohibitive voice intention $(\beta=0.34$, $p<0.01$ ), but not on promotive voice intention. After entering felt guilt, the relationship between UPB and prohibitive voice intention becomes non-significant $(\beta=-0.05$, n.s. $)$.

We further used Hayes's (2013) bootstrapping procedure to test the mediation effects. Results show that felt guilt mediates the relationship between UPB acting and prohibitive voice intention (indirect effect $=0.17$, bootstrapping $\mathrm{SE}=0.07, p<0.05,95 \% \mathrm{CI}=[0.05,0.31])$, but does not mediate the relationship between UPB acting and promotive voice intention (indirect effect $=0.08$, bootstrapping
Table 2 Multivariate regression results in Study 1A

\begin{tabular}{lccclll}
\hline & Felt guilt & \multicolumn{2}{l}{$\begin{array}{l}\text { Prohibitive voice } \\
\text { intention }\end{array}$} & \multicolumn{2}{l}{$\begin{array}{l}\text { Promotive voice } \\
\text { intention }\end{array}$} \\
\cline { 3 - 4 } \cline { 6 - 7 } \cline { 6 - 7 } & Model 1 & Model 2 & Model 3 & & Model 4 & Model 5 \\
\hline Sex & -0.04 & 0.03 & 0.04 & & 0.06 & 0.06 \\
Age & 0.17 & -0.01 & -0.07 & & 0.03 & 0.01 \\
Work tenure & -0.12 & 0.17 & 0.21 & & 0.14 & 0.15 \\
UPB acting & $0.72^{* * *}$ & $0.19^{*}$ & -0.05 & & $0.18^{*}$ & 0.08 \\
Felt guilt & & & $0.34^{* *}$ & & 0.14 \\
$R^{2}$ & 0.54 & 0.06 & 0.11 & 0.06 & 0.07 \\
$F$ value & $40.62^{* * *}$ & $2.09^{\dagger}$ & $3.42^{* *}$ & & $2.09^{\dagger}$ & 1.95 \\
$R^{2}$ change & 0.54 & 0.06 & 0.05 & 0.06 & 0.01 \\
\hline
\end{tabular}

$N=159$. Standardized coefficients were reported

${ }^{\dagger} p<0.10,{ }^{*} p<0.05, * * p<0.01, * * * p<0.001$

$\mathrm{SE}=0.07$, n.s., $95 \% \mathrm{CI}=[-0.06,0.21])$. Therefore, Hypothesis $2 \mathrm{a}$ is supported, but not Hypothesis $2 \mathrm{~b}$.

\section{Study 1 A Discussion}

Through scenario manipulation, we tested the causal relationship from UPB acting to felt guilt and then intention of two kinds of voice in Study 1A. Despite the internal validity, this study has some limitations. First, the mediation of felt guilt in the relationship between UPB and promotive voice was not supported in our experiment due to the relatively low correlation between felt guilt and promotive voice. This may not be surprising because at an acute level, research show that prohibitive voice helps to decrease state negative emotions (such as guilty in this study) while promotive voice does not (Starzyk et al. 2018). However, moral cleansing process is not limited in a short time (Cryder et al. 2012) and we still need more evidence to detect this relationship.

Second, we measured voice intention instead of actual voice behavior due to the constraint of the scenario-based experiment. Although intention is a proximal indicator of behavior, we still need more support on the actual behavior. Thus, it would be better to test if UPB actors who feel guilty would actually engage in prohibitive and promotive voice. Third, the method of scenario-based experiment is limited in realism in that participants read and respond to a hypothetical scenario instead of actually going through these behaviors or situations (see Aguinis and Bradley 2014 for a review). In our study, for example, it may be difficult to distinguish whether the participants react to the described situation as bystanders or as UPB actors in the context. ${ }^{2}$

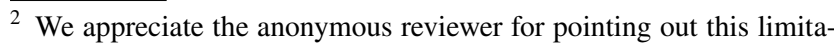
tion. 
We therefore designed Study 1B to exclude this alternative explanation.

\section{Study 1B}

\section{Participants and Procedure}

For this study, ${ }^{3}$ we recruited 232 college students (including both undergraduate and graduate) via the alumni network of one coauthor. They were told to join an advertisement consulting team and design an advertisement for a client who sell face masks. The link of the mask-selling advertisement task was sent to participants via their email addresses, and participants could finish the task online. We finally received 203 completed responses (87.5\% response rate). During the study, participants' voluntariness and confidentiality were ensured. At the end, each participant received a compensation of 20 RMB (equal to 3 US dollars). Among the 203 participants, $57.1 \%$ were female, $64.5 \%$ were undergraduate students, and they averaged at 22.3 years old $(\mathrm{SD}=2.7)$.

\section{Context and Task}

We introduced to the participants that we were a business consulting team and our current job was to help a face mask manufacturer design an advertisement to sell 200,000 face masks. We chose this task because the study was conducted during the worldwide COVID-19 pandemic, a serious global health threat. The public was aware that the virus mainly spreads through airborne transmission and people can be protected from the virus by wearing a facial mask. The surgical mask is preferred over general dust mask because the latter can only filter dust particulate, and surgical masks have more stricter qualification standards and can filter much smaller virus particulate. So, surgical masks can better protect people from the virus than dust mask. Accordingly, the price of surgical masks usually is higher than that of dust masks, which the public was also aware of. In addition, despite the higher price, the demand for surgical masks was quite high, due to the wide-spread COVID-19.

Then, the participants read that there were two kinds of face masks, half of them were surgical mask, and the other half dust mask. The two kinds of masks looked the same. They only differed in the material that the surgical mask contained electret melt-blown, making it able to block bacteria, while the dust mask only contained non-woven, making it able to block dust or smell, but not bacteria. Furthermore, the price of each surgical mask sold online was averaged at

\footnotetext{
3 This study was approved by Internal Review Board at Peking University (\#2020-01).
}

$2 \mathrm{RMB}$, while the dust mask was sold online with the average price of $1 \mathrm{RMB}$. However, the manufacturer told us that the masks were accidentally mixed up during the change of warehouse, making it hard to distinguish since the two kinds of masks looked the same. According to the manufacturer, the cost for each surgical mask was $0.8 \mathrm{RMB}$, while the dust mask 0.3 RMB. In addition, the manufacturer promised us $30 \%$ of the sales profit.

Next, we told the participants that we might have two alternatives to sell these masks. First, we might sell all the masks as "surgical mask" to make the most profit. Second, we might sell all the masks as merely "dust mask". As we explained early, it is reasonable to expect that the participants were aware of both the benefits to the consulting team and the sanitary consequences for the customers of selling dust masks for surgical ones. Specifically, the consulting team could benefit more if all the masks were sold as surgical masks; while customers might not only cost more money, but also risk their lives because of the misusage of dust masks as surgical ones. In such a design, we could distinguish UPB (i.e., selling all the masks as surgical ones) from non-UPB (e.g., selling all the masks as dust masks) acting.

\section{Measures}

\section{UPB Acting}

In the task, we asked the participants to design an advertisement of the face mask, including the following four aspects of the masks. For each aspect, participants could either choose from two solutions we offered or make their own design.

First, participants needed to choose the label of the masks. Two options we offered were surgical masks ("surgical masks, medically sterilized”) or dust masks ("dust mask, anti-haze").

Second, participants needed to decide the price of the masks. We told participants that masks were priced in 3 ways: 20 pieces, 50 pieces, and 100 pieces. Two options we offered were "surgical masks, 48 RMB for 20 pieces, 100 RMB for 50 pieces, 180 RMB for 100 pieces" and "dust masks, 24 RMB for 20 pieces, 50 RMB for 50 pieces, 90 RMB for 100 pieces".

Third, participants needed to declare the material of the masks. We emphasized the difference between the two kinds of masks and provided the participants a picture to show the material of the mask. We offered two material statements (one describing surgical mask material and the other describing dust mask material). The two statements were "surgical masks, electret melt-blown inside, effectively blocking bacteria, necessity of traveling during COVID19 " and "dust masks, non-woven inside, effectively blocking dust, necessity of domestic living and traveling." 
Fourth, participants needed to provide the qualification of the masks in the advertisement. In particular, the surgical masks were qualified with a surgical mask quality test, export certification, and drug administration permission, while the dust masks had a dust mask quality test and export certification, but did not have a drug administration permission. We provided pictures of the qualification certification for the two kinds of masks for the participants to choose from, while also left a blank for them to make their own design (they could choose which qualifications to be included for this aspect).

For each of the above four aspects of the mask advertisement, participants who chose "surgical mask" option (e.g., "surgical masks, medically sterilized" for the label of the masks) got 1 score on UPB acting, and those who chose "dust mask" option or designed to sell the masks as a mixed pack (e.g., "tell the customers that the masks are mixed with both surgical and dust masks and they will receive a mixed pack of masks based on luck" for the label of the masks) got 0 on UPB acting, resulting in a total score on UPB acting from 0 to 4 .

\section{Felt Guilt}

After finishing the task, we used the same 12 items as in Study 1A to measure felt guilt $(\alpha=0.93)$.

\section{Promotive Voice}

After the measurement of felt guilt, we asked the participants if they had any concerns or suggestions about the current task or the future operation of this business consulting team. We left an optional blank and participants could choose to fill in any suggestions or just skip it.

About $24.6 \%$ of participants answered this question. Some example answers to this question include, "We might make compensation to the customers" and "We might improve customer service and deal with customers' complaints with more patience." We reviewed all the answers to this question and found that all the participants who answered this question only provided suggestions, but not concerns or criticism. This is understandable as the work procedure of this consulting team had no obvious errors. We then decided to code it as a dummy variable of promotive voice. So, promotive voice was coded as 1 if participants provided any suggestions, and a blank or "No" response were coded as 0 .

\section{UPB Perception}

We used 4 items of the initial 6-item UPB scale (Umphress et al. 2010) to measure their UPB perception, or the extent to which participants agreed that they had conducted UPB in the task to validate our measure of UPB acting. One sample item was "To help our team, I had exaggerated the truth about the product to customers and clients." Two items "To help our team, I had given a good recommendation on the behalf of an incompetent employee in the hope that the person will become another organization's problem instead of my own;" and "To help our team, I had withheld issuing a refund to a customer or client accidentally overcharged" were deleted due to inappropriateness in the current study $(\alpha=0.96)$.

\section{Perceived Unethicality of the Designed Advertisement}

Though not hypothesized, one purpose of Study 1B was to test whether participants conducted UPB could actually recognize what they had done was unethical. In other words, whether they could be aware of the unethicality from the actor instead of the bystander perspective. At the end of the survey, we used four items to measure whether participants perceived what they had designed were unethical. Three items were adapted from Graham et al.'s (2020) research, a sample item was "Concerning the design of the advertisements, I know what I have done is immoral." We composed a fourth item "Concerning the design of the advertisements, I know what I have done is morally unacceptable" $(\alpha=0.97)$.

\section{Control Variables}

We controlled for participants' age (in years) and sex (0-male, 1-female) given their possible influence on felt guilt and voice behavior (e.g., Fuller et al. 2006; Linda et al. 2016). In addition, since participants' education (0-undergraduate student, 1-graduate student) correlated highly with participants' age $(r=0.68, p<0.001)$, we did not include it as a control variable.

\section{Results}

Table 3 shows the means, standard deviations, and correlations among the focal variables in this study.

\section{Validation of the Measure of UPB Acting}

Prior to testing our hypotheses, we validated the measurement of UPB acting by examining the correlation of our measure of UPB acting and the participants' UPB perception. Results show that they are strongly correlated $(r=0.62$, $p<0.001$ ), suggesting high validity of our measurement of UPB acting. 
Table 3 Means, standard deviations, and correlations of variables in Study 1B
Table 4 Multivariate regression results in Study 1B

\begin{tabular}{lrllllllll}
\hline & $M$ & SD & 1 & 2 & 3 & 4 & 5 & 6 & 7 \\
\hline (1) Age & 22.25 & 2.69 & & & & & & & \\
(2) Sex & 0.57 & 0.50 & $-.19^{* *}$ & & & & & & \\
(3) Education & 0.35 & 0.48 & $0.68^{* *}$ & -0.04 & & & & & \\
(4) UPB acting & 1.14 & 1.61 & 0.02 & -0.09 & -0.02 & & & & \\
(5) UPB perception & 2.66 & 1.65 & -.04 & -0.02 & -0.06 & $0.62^{* *}$ & $(0.96)$ & & \\
(6) Perceived unethicality & 2.71 & 1.74 & -.02 & -0.03 & -0.06 & $0.60^{* *}$ & $0.86^{* *}$ & $(0.97)$ \\
$\quad$ of the designed advertise- & & & & & & & & & \\
$\quad$ ment & & & & & & & & & \\
(7) Felt guilt & 3.03 & 1.18 & 0.01 & -0.02 & 0.02 & $0.39^{* *}$ & $0.69^{* *}$ & $0.73^{* *}$ & $(0.93)$ \\
(8) Promotive voice & 0.25 & 0.43 & 0.01 & 0.03 & 0.01 & $0.45^{* *}$ & $0.30^{* *}$ & $0.31^{* *}$ & $0.30^{* *}$ \\
\hline
\end{tabular}

Sex: 0-male, 1-female. Education: 0-undergraduate student, 1-graduate student. UPB acting: 0-4 score. Promotive voice: 1 -voiced, 0 -no voice. Numbers in parentheses are Cronbach's $\alpha . N=203$

$* p<0.05, * * p<0.01$

\begin{tabular}{|c|c|c|c|c|c|c|c|c|c|}
\hline & \multirow{3}{*}{$\begin{array}{l}\text { Felt guilt } \\
\text { Model } 1 \\
\beta\end{array}$} & \multicolumn{8}{|c|}{ Promotive voice $(1=$ voiced, $0=$ no voice $)$} \\
\hline & & \multicolumn{4}{|l|}{ Block 1} & \multicolumn{4}{|l|}{ Block 2} \\
\hline & & $b$ & SE & Wald $\chi^{2}$ & OR & $b$ & SE & Wald $\chi^{2}$ & OR \\
\hline Age & 0.01 & 0.01 & 0.07 & 0.02 & 1.01 & 0.01 & 0.07 & 0.01 & 1.01 \\
\hline Sex & 0.02 & 0.47 & 0.39 & 1.47 & 1.60 & 0.42 & 0.39 & 1.15 & 1.52 \\
\hline UPB acting & $0.39 * * *$ & $0.63 * * *$ & 0.11 & 34.95 & 1.88 & $0.54 * * *$ & 0.11 & 23.52 & 1.73 \\
\hline Felt guilt & & & & & & $0.36 * *$ & 0.17 & 4.45 & 1.43 \\
\hline$R^{2} /$ Nagelkerke $R^{2}$ & 0.15 & 0.26 & & & & 0.29 & & & \\
\hline-2 Log likelihood & & 186.88 & & & & 182.28 & & & \\
\hline
\end{tabular}

$N=203$

$* * p<0.01, * * * p<0.001$

\section{Perceived Unethicality of the Designed Advertisement}

Results show that 123 participants did not conduct UPB (with a score of 0), while 19 participants scored 1, 9 participants scored 2, 14 participants scored 3, and 38 participants scored 4 for UPB acting. ANOVA results indicate that these five groups varied in their perceived unethicality of what they have designed $[F(4,198)=29.32, p<0.001]$. Post hoc analyses reveal that those did not conduct UPB perceived significantly less unethicality of what they have done (mean $=1.96, \mathrm{SD}=1.16)$ than those scored 1 (mean $=2.88$, $\mathrm{SD}=1.53, p<0.01)$, those scored 2 (mean $=3.08, \mathrm{SD}=1.43$, $p<0.05)$, those scored 3 (mean $=3.53, \mathrm{SD}=1.57, p<0.001)$, and those scored 4 for UPB acting (mean $=4.66, \mathrm{SD}=1.84$, $p<0.001$ ). These results suggest that UPB actors did recognize their behaviors as unethical, especially those scored 4 for UPB acting. Correlation results also suggest that those who conducted more UPB were more likely to perceive their design of the advertisement as unethical, with our measure of UPB acting correlates significantly with perceived unethicality of the designed advertisement $(r=0.60, p<0.01)$.

\section{Tests of the Hypotheses}

Table 4 reports the regression results. As shown in Model 1, the effect of UPB acting on felt guilt is significant $(\beta=0.39$, $p<0.001$ ), thus supporting Hypothesis 1.

Since promotive voice in this study is a dichotomous variable, we ran a logistic regression to test Hypothesis $2 \mathrm{~b}$, which suggests UPB acting positively related to promotive voice through the mediation of felt guilt. As shown in block 1 (Table 4), UPB acting is significantly related to the likelihood of promotive voice, $b=0.63, \mathrm{SE}=0.11$, Wald $\chi^{2}(1)=34.95, p<0.001$; odds ratio $(\mathrm{OR})=1.88$, indicating the more participants conduct UPB, the more likely they would engage in promotive voice. As shown in block 2 (Table 4), felt guilt has a significant influence on the likelihood of promotive voice, $b=0.36, \mathrm{SE}=0.17$, Wald $\chi^{2}(1)=4.45, p<0.01$; odds ratio $(\mathrm{OR})=1.43$.

We also applied Hayes's (2013) bootstrapping procedure (bootstrap $=5000$ ) to test the mediation effects. Results show that felt guilt mediates the relationship between UPB acting and promotive voice (indirect effect $=0.10$, bootstrapping 
$\mathrm{SE}=0.06,95 \% \mathrm{CI}=[0.01,0.23])$, providing support for Hypothesis $2 b$.

\section{Study 1B Discussion}

In Study 1B, we created a context and designed a task for participants to actually conduct UPB and voice behavior. The results are consistent with those in Study 1A. Through Study $1 \mathrm{~A}$ and $1 \mathrm{~B}$, we tested the causal relationship from UPB to felt guilt and then (prohibitive and/or promotive) voice intention and behavior. The two studies provide a solid evidence for internal validity. However, they provide limited evidence for external validity. In addition, we did not test the moderation effect of MIS. We therefore conducted a field study in Study 2 to address these limitations.

\section{Study 2}

\section{Participants and Procedure}

We conducted a two-wave survey with a time lag of two weeks to test the proposed model in the work context. At Time 1, we invited 274 part-time MBA students from a business school in Northern China to participate in our study via email, with a link to our study enclosed. We received responses from $228 \mathrm{MBA}$ students (83.2\% response rate) who provided their demographic information, UPB, moral identity (symbolization and internalization), and felt guilt. Two weeks later, we sent an email to these MBA students with a link to the second survey to measure their prohibitive and promotive voice during the past two weeks. We chose a time interval of 2 weeks for two reasons. First, according to previous voice research (e.g., Burris et al. 2017), a time duration of two weeks was enough for voice behavior to emerge. Second, we chose a relatively shorter time interval to ensure a higher response rate from the participants at phase 1. Data from the two surveys were matched based on their student ID number, and confidentiality was guaranteed. Finally, 177 valid responses were matched $(64.6 \%$ overall response rate).

Among these 177 participants, $67.8 \%$ were male, their average age was 32.1 years old $(\mathrm{SD}=3.6)$, and their average work tenure was 8.9 years $(\mathrm{SD}=3.4)$. These participants worked in different departments from various organizations, including HR department, marketing, sales, R\&D, finance, and other departments.

\section{Measures}

\section{UPB Acting}

UPB acting was measured with the 6-item scale developed by Umphress et al. (2010). Participants were asked to recall how often they have engaged in the following behaviors such as "To help my organization, I misrepresented the truth to make my organization look good;" and "To help my organization, I exaggerated the truth about my company's products or services to customers and clients" $(\alpha=0.73)$.

\section{Felt Guilt}

We used the same 12 items as in Studies $1 \mathrm{~A}$ and $1 \mathrm{~B}$ to measure felt guilt after their recall of UPB acting $(\alpha=0.85)$.

\section{Moral Identity Symbolization (MIS)}

We measured participants' MIS with Reed and Aquino's (2003) 5-item subscale. In this scale, characteristics including caring, compassionate, fair, friendly, generous, helpful, hardworking, honest, and kind were introduced, and participants were asked to visualize in their mind the kind of person who had these characteristics. Next, participants rated the extent to which they agreed with each of the 5 statements, such as "I am actively involved in activities that communicate to others that I have these characteristics" $(\alpha=0.73)$.

\section{Prohibitive and Promotive Voice}

We used Liang et al.'s (2012) scale to measure participants' prohibitive and promotive voice in the work context. Following Burris et al. (2017) approach to measure voice frequency, we asked participants to rate the frequency they had acted as stated in the past 2 weeks ( $\alpha=0.83$ for prohibitive voice, and 0.90 for promotive voice).

\section{Control Variables}

Consistent with Study 1B, we controlled for participants' age (in years) and sex (0-male, 1-female). Furthermore, we controlled for work tenure (in years) since employees with longer tenure may feel more comfortable to voice (Detert and Burris 2007). Additionally, following previous studies, we controlled for employees' MII, since MII has been found to influence employees' ethical behavior (Lavelle et al. 2018; Zhu et al. 2020). The 5-item subscale of moral identity (Reed and Aquino 2003) was used to measure MII $(\alpha=0.82)$.

\section{Results}

\section{Test of Construct Validity}

We first performed confirmatory factor analyses (CFAs) on the variables in our study using Mplus 8.4. Due to the relatively small sample size $(N=177)$, we created several 
Table 5 Results of confirmatory factor analysis in Study 2

\begin{tabular}{|c|c|c|c|c|c|c|c|c|}
\hline Model & $\chi^{2}$ & df & $\Delta \chi^{2}$ & $\Delta \mathrm{df}$ & CFI & TLI & SRMR & RMSEA \\
\hline Six-factor model (UPB, MII, MIS, FG, PHV, PMV) & 207.79 & 104 & & & 0.93 & 0.91 & 0.06 & 0.08 \\
\hline Five-factor model (UPB, MII + MIS, FG, PHV, PMV) & 296.27 & 109 & $88.48 * * *$ & 5 & 0.87 & 0.84 & 0.09 & 0.10 \\
\hline Five-factor model (UPB, MII, MIS, FG, PHV + PMV) & 259.19 & 109 & $51.40 * * *$ & 5 & 0.90 & 0.87 & 0.06 & 0.09 \\
\hline Four-factor model (UPB, MII + MIS, FG, PHV + PMV) & 345.84 & 113 & $138.05 * * *$ & 9 & 0.84 & 0.81 & 0.09 & 0.11 \\
\hline Two-factor model (UPB + MII + MIS + FG, PHV + PMV) & 487.56 & 116 & $279.77 * * *$ & 12 & 0.74 & 0.70 & 0.09 & 0.14 \\
\hline One-factor model (UPB + MII + MIS + FG + PHV + PMV) & 998.74 & 119 & $790.95 * * *$ & 15 & 0.39 & 0.30 & 0.15 & 0.20 \\
\hline
\end{tabular}

“+” Indicates factors combined

$U P B$ unethical pro-organizational behavior acting, $M I I$ moral identity internalization, $M I S$ moral identity symbolization, $F G$ felt guilt, $P H V$ prohibitive voice, $P M V$ promotive voice

$* * * p<.001$

Table 6 Means, standard deviations, and correlations of variables in Study 2

\begin{tabular}{lrllllllllll}
\hline Variable & M & SD & 1 & 2 & 3 & 4 & 5 & 6 & 7 & 8 & 9 \\
\hline (1) Age & 32.13 & 3.56 & & & & & & & & \\
(2) Sex & 0.32 & 0.47 & $-0.16^{*}$ & & & & & & & \\
(3) Work tenure & 8.93 & 3.35 & $0.87^{* *}$ & -0.12 & & & & & & \\
(4) UPB acting & 3.66 & 1.08 & -0.01 & $-0.17^{*}$ & -0.02 & $(0.73)$ & & & & \\
(5) Moral identity internalization (MII) & 5.62 & 1.10 & 0.05 & 0.04 & 0.05 & $-0.17^{*}$ & $(0.82)$ & & & \\
(6) Moral identity symbolization (MIS) & 4.73 & 0.96 & 0.07 & 0.10 & 0.03 & 0.15 & $0.28^{*}$ & $(0.73)$ & & \\
(7) Felt guilt & 5.29 & 0.81 & -0.06 & 0.14 & -0.10 & $0.14^{\dagger}$ & $0.47^{* *}$ & $0.41^{* *}$ & $(0.85)$ & & \\
(8) Prohibitive voice & 5.28 & 0.93 & $0.20^{* *}$ & -0.08 & $0.26^{* *}$ & $0.13^{\dagger}$ & 0.07 & $0.23^{* *}$ & $0.23^{* *}$ & $(0.83)$ \\
(9) Promotive voice & 5.62 & 0.92 & $0.28^{* *}$ & 0.01 & $0.29^{* *}$ & 0.04 & $0.15^{* *}$ & $0.17^{* *}$ & $0.23^{* *}$ & $0.74^{* *}$ & $(0.90)$ \\
\hline
\end{tabular}

$N=177$. Numbers in parentheses are Cronbach's $\alpha$

${ }^{\dagger} p<0.10, * p<0.05, * * p<0.01$

item-parcels for the variables of interest. As recommended by Hau and Marsh (2004) and Yang et al. (2010), we used the item-to-construct balancing strategy to form 3 parcels for UPB acting, 6 parcels for felt guilt, 2 for MII, 2 for MIS, 2 for prohibitive voice, and 2 for promotive voice. As showed in Table 5, the six-factor model fitted best to our data $\left(\chi^{2}=207.79, \mathrm{df}=104, \mathrm{RMSEA}=0.08, \mathrm{CFI}=0.93\right.$, $\mathrm{TLI}=0.91, \mathrm{SRMR}=0.06$ ), suggesting that the six variables have good discriminant validity.

\section{Test of Hypotheses}

Table 6 reports means, standard deviations, and correlations of the study variables. As shown in Table 6, UPB is positively correlated with felt guilt $(r=0.14, p<0.10)$, and felt guilt is positively correlated with prohibitive $(r=0.23$, $p<0.01)$ and promotive voice $(r=0.23, p<0.01)$.

We conducted ordinary least square (OLS) regressions to test our hypotheses. Results are shown in Table 7. Model 2 shows that UPB acting is positively related to felt guilt $(\beta=0.25, p<0.001)$, thus supporting Hypothesis 1 .
Hypotheses $2 \mathrm{a}$ and $2 \mathrm{~b}$ suggest that felt guilt mediates the relationship between UPB acting and prohibitive and promotive voice, respectively. Results in Table 7 show that UPB acting significantly predicts felt guilt (Model 2: $\beta=0.25, p<0.001)$; felt guilt is positively related to prohibitive (Model 4: $\beta=0.30, p<0.01$ ) and promotive voice (Model 7: $\beta=0.24, p<0.01$ ). Although UPB acting does not significantly affect prohibitive (Model 3: $\beta=0.14, p<0.10$ ) and promotive voice (Model 6: $\beta=0.08$, n.s.), it was not a necessary condition for a mediating effect (Preacher and Hayes 2008).

We further used the bootstrapping procedure (bootstrap $=5000$ ) to test these mediation effects (Hayes 2013). Results show that the indirect effect of UPB acting on prohibitive voice through felt guilt is 0.07 (bootstrapped $\mathrm{SE}=0.03$ ), and the $95 \% \mathrm{CI}$ is [0.03, 0.14], supporting Hypothesis 2a. Moreover, the indirect effect of UPB acting on promotive voice through felt guilt is 0.05 (bootstrapped $\mathrm{SE}=0.02$ ), and the $95 \% \mathrm{CI}$ is $[0.02,0.11]$, supporting Hypothesis $2 b$.

Hypothesis $3 \mathrm{a}$ and $3 \mathrm{~b}$ depict that MIS moderates the relationship between felt guilt and prohibitive and promotive 
Table 7 OLS regression results in Study 2

\begin{tabular}{|c|c|c|c|c|c|c|c|c|c|}
\hline & \multirow[t]{2}{*}{ Variable } & \multicolumn{2}{|l|}{ Felt guilt } & \multicolumn{3}{|c|}{ Prohibitive voice } & \multicolumn{3}{|c|}{ Promotive voice } \\
\hline & & Model 1 & Model 2 & Model 3 & Model 4 & Model 5 & Model 6 & Model 7 & Model 8 \\
\hline \multirow[t]{4}{*}{ Control variable } & Age & 0.13 & 0.13 & -0.09 & -0.13 & -0.15 & 0.12 & 0.09 & 0.10 \\
\hline & Sex & $0.15^{*}$ & $0.20 * *$ & -0.02 & -0.08 & -0.13 & 0.08 & 0.03 & -0.01 \\
\hline & Work tenure & -0.21 & -0.21 & $0.33^{*}$ & $0.39 * *$ & $0.40 * *$ & 0.18 & $0.24^{\dagger}$ & $0.23^{\dagger}$ \\
\hline & MII & $0.48 * * *$ & $0.52 * * *$ & 0.08 & -0.07 & -0.08 & $0.16^{*}$ & 0.03 & 0.04 \\
\hline Independent variable & UPB acting & & $0.25 * * *$ & $0.14^{\dagger}$ & 0.07 & 0.04 & 0.08 & 0.02 & 0.01 \\
\hline Mediator & Felt guilt & & & & $0.30 * *$ & $0.30 * *$ & & $0.24 * *$ & $0.26^{* *}$ \\
\hline Moderator & MIS & & & & & $0.15^{\dagger}$ & & & 0.04 \\
\hline Interaction term & Felt guilt * MIS & & & & & $0.19 *$ & & & $0.18^{*}$ \\
\hline$R^{2}$ & & 0.26 & 0.32 & 0.09 & 0.15 & 0.21 & 0.12 & 0.16 & 0.19 \\
\hline$F$ value & & $14.89 * * *$ & $15.92 * * *$ & $3.48 * *$ & $5.16^{* * *}$ & $5.45 * * *$ & $4.55^{* *}$ & $5.24 * * *$ & $4.82 * * *$ \\
\hline$R^{2}$ change & & & $0.06 * * *$ & & $0.06 * *$ & $0.05 * *$ & & $0.04 * *$ & $0.03 *$ \\
\hline
\end{tabular}

$N=177$. Standardized coefficients were reported

${ }^{\dagger} p<0.10, * p<0.05, * * p<0.01, * * * p<0.001$

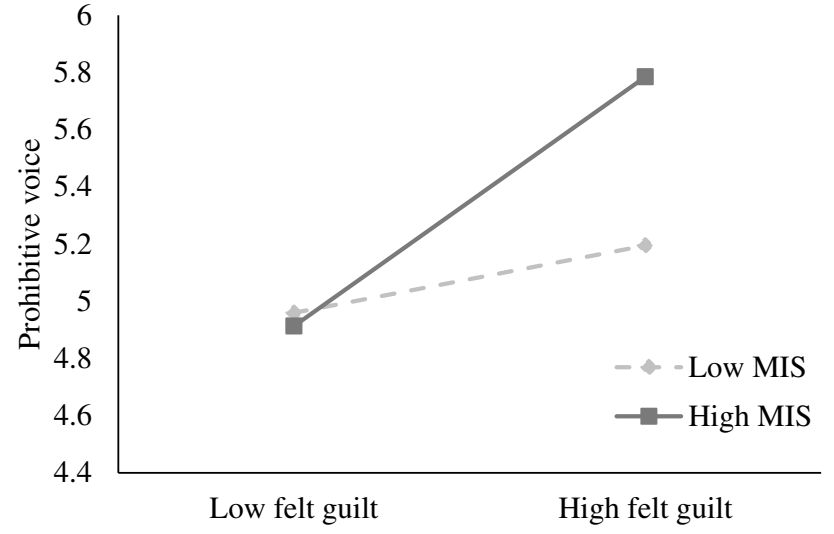

Fig. 1 The moderating effect of MIS on felt guilt and prohibitive voice in Study 2

voice. Following Aiken and West (1991), Model 5 and Model 8 (Table 7) show that the interaction between felt guilt and MIS significantly predicts prohibitive voice (Model 5: $\beta=0.19, p<0.05$ ) and promotive voice (Model 8: $\beta=0.18, p<0.05)$, thus providing support for Hypothesis $3 \mathrm{a}$ and $3 \mathrm{~b}$.

In order to further demonstrate the moderating effects, we plotted the moderating effect and tested the simple slopes under the high $(+1 \mathrm{SD})$ vs. low $(-1 \mathrm{SD})$ MIS condition. As shown in Fig. 1, when MIS is high, felt guilt is positively related to prohibitive voice $(b=0.53, \mathrm{SE}=0.14, p<0.001)$; when MIS is low, the relationship between felt guilt and prohibitive voice is not significant $(b=0.14, \mathrm{SE}=0.11$, $p>0.10$ ).

As shown in Fig. 2, when MIS is high, felt guilt is positively related to promotive voice $(b=0.48, \mathrm{SE}=0.14$, $p<0.001)$; when MIS is low, the relationship between

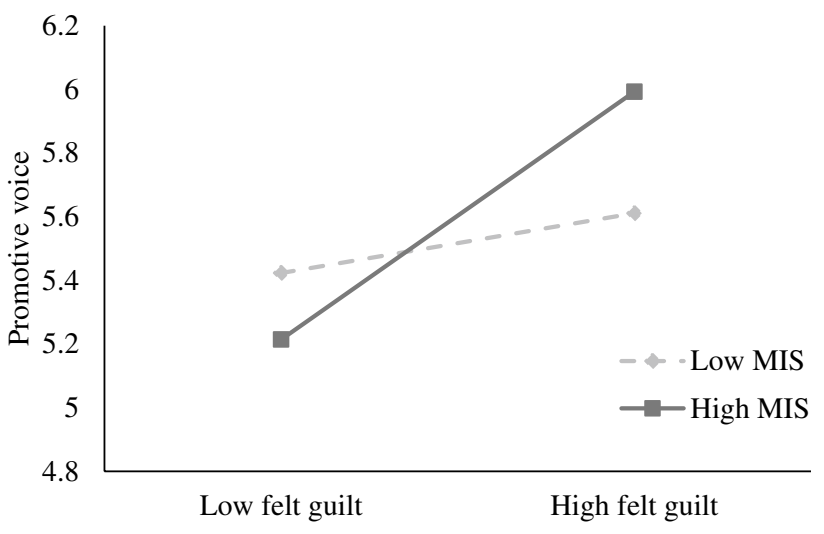

Fig. 2 The moderating effect of MIS on felt guilt and promotive voice in Study 2

felt guilt and promotive voice is not significant $(b=0.12$, $\mathrm{SE}=0.11, p>0.10)$.

Hypothesis $4 \mathrm{a}$ and $4 \mathrm{~b}$ predict that MIS moderates the mediation effect of felt guilt between the relationship of UPB acting and prohibitive and promotive voice, respectively. We applied the bootstrapping procedure (bootstrap $=5000$, Model 14) in SPSS to test these moderated mediation effects. Results show that the moderated mediation effect of MIS on the relationship between UPB acting and prohibitive voice through felt guilt is 0.04 (bootstrapped $\mathrm{SE}=0.02,95 \% \mathrm{CI}=[0.004,0.091])$. Specifically, when MIS is high, the mediation effect of felt guilt between UPB acting and prohibitive voice is significant (mediation effect $=0.10$, bootstrapped $\mathrm{SE}=0.04,95 \% \mathrm{CI}=[0.04,0.20])$; when MIS is low, the mediation effect is not significant (mediation effect $=0.03$, bootstrapped $\mathrm{SE}=0.03,95 \% \mathrm{CI}=[-0.02$, $0.09])$. 


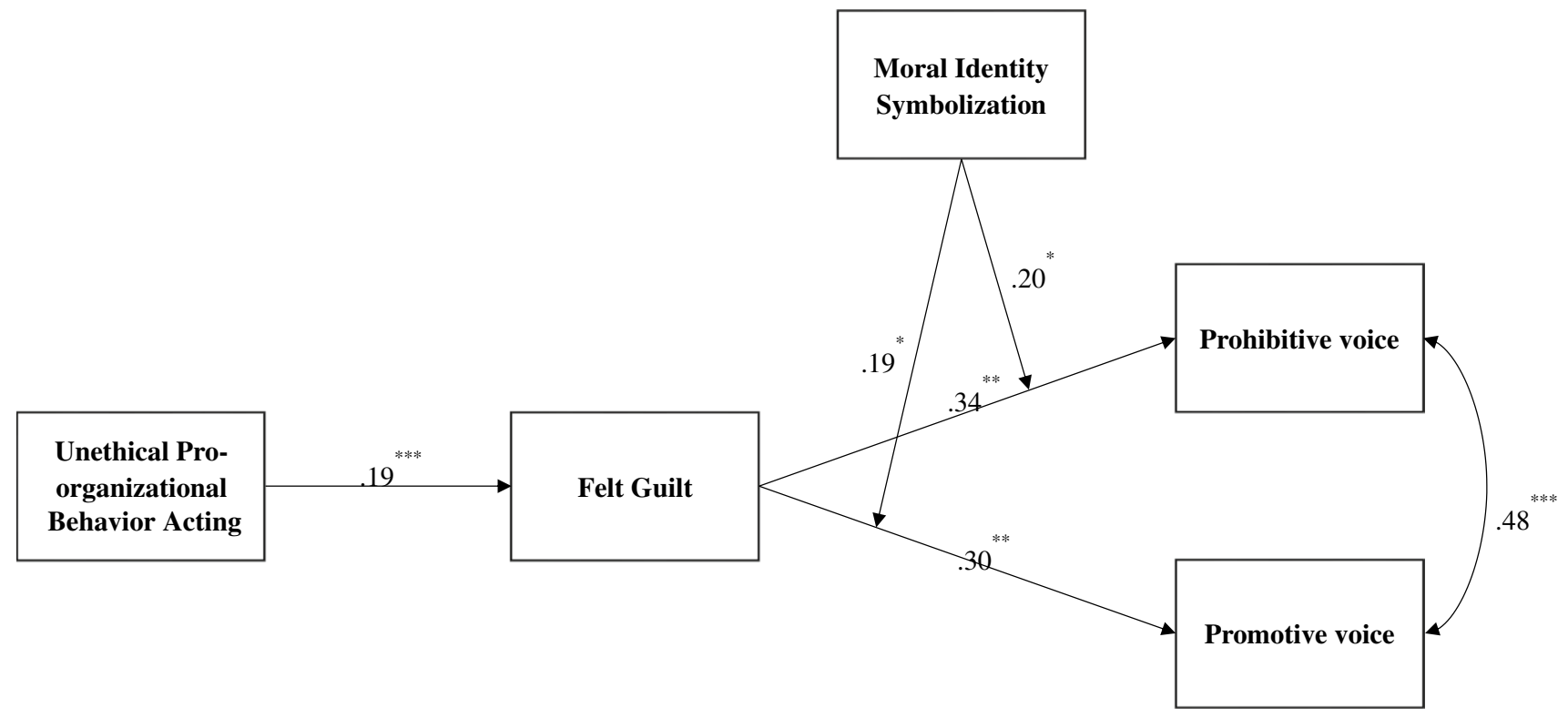

Fig. 3 Path analysis results of the research model in Study 2. Note standardized path coefficients are presented. * $p<.05, * * p<.01, * * * p<.001$

Moreover, the moderated mediation effect of MIS on the relationship between UPB acting and promotive voice through felt guilt is 0.04 (bootstrapped $\mathrm{SE}=0.02,95 \%$ $\mathrm{CI}=[0.001,0.088]$, excluding zero). Specifically, when MIS is high, the mediation effect of felt guilt between UPB acting and promotive voice is significant (mediation effect $=0.09$, bootstrapped $\mathrm{SE}=0.04,95 \% \mathrm{CI}=[0.03,0.19]$ ); when MIS is low, the mediation effect is not significant (mediation effect $=0.02$, bootstrapped SE $=0.03,95 \% \mathrm{CI}=[-0.02$, $0.08])$. Thus, results provide support for Hypothesis $4 \mathrm{a}$ and $4 b$.

\section{Robustness Check}

We also applied Mplus 8.4 to simultaneously include two dependent variables and test our hypotheses as a robustness check. Figure 3 depicts the standardized coefficients of path analysis and these results are consistent with the regression results.

Specifically, Hypothesis 1 is supported in that UPB acting is positively related to felt guilt $(\beta=0.19, p<0.001)$. Results also show that felt guilt mediates the relationship between UPB acting and prohibitive voice (95\% bias corrected bootstrapped $\mathrm{CI}=[0.03,0.14])$, and the relationship between UPB acting and promotive voice (95\% bias corrected bootstrapped $\mathrm{CI}=[0.02,0.11])$, supporting Hypotheses $2 \mathrm{a}$ and $2 \mathrm{~b}$. In addition, MIS moderates the relationship between guilt and prohibitive voice (interaction term $b=0.20, \mathrm{SE}=0.09, p<0.05$ ), and the relationship between felt guilt and promotive voice (interaction term $b=0.19$, $\mathrm{SE}=0.09, p<0.05)$, supporting Hypotheses $3 \mathrm{a}$ and $3 \mathrm{~b}$.
Moreover, MIS moderates the mediation effect of felt guilt between UPB acting and prohibitive voice $(95 \%$ bias corrected bootstrapped $\mathrm{CI}=[0.01,0.17])$, and the mediation of felt guilt between UPB acting and promotive voice (95\% bias corrected bootstrapped $\mathrm{CI}=[0.003,0.166])$, supporting Hypotheses $4 \mathrm{a}$ and $4 \mathrm{~b}$.

\section{Study 2 Discussion}

Through a two-wave survey, we measured employees' past UPB acting, their felt guilt, and their subsequent actual prohibitive and promotive voice. Consistent with Studies 1A and 1B, results of Study 2 showed that employees' UPB could increase their subsequent voice (both prohibitive and promotive voice), through the mediating role of felt guilt. Furthermore, Study 2 complemented Study $1 \mathrm{~A}$ by testing the effect of UPB acting on actual prohibitive and promotive voice behaviors in the workplace rather than voice behavior intentions, via the mediation of felt guilt. Study 2 also generalized the findings of Study 1B by recruiting participants with work experiences instead of student participants. Therefore, Study 2 provides evidence on external validity of our findings from Studies 1A and 1B. Moreover, in Study 2, we tested MIS's role to moderate the mediating process of felt guilt between UPB acting and (a) prohibitive voice, and (b) promotive voice. 


\section{General Discussion}

Applying a moral cleansing theory, the present study investigates the outcome of UPB from the perspective of the focal actor. Specifically, through three studies, we found that UPB acting consistently provoked feelings of guilt, and subsequent voice behaviors. Moreover, our results also showed that MIS moderated the relationship between felt guilt and two kinds of voice behavior such that felt guilt predicted two kinds of voice behavior only when employees had a higher level of MIS.

\section{Theoretical Contribution}

This study devotes to make contribution to the literature of UPB and voice in the following aspects. First, it advances the current literature of UPB which mainly focuses on antecedence of UPB. Extant literature differentiates UPB from other unethical behaviors in terms of the intention. In particular, since UPB is conducted in the purpose of benefiting the organization, some researchers draw on a moral disengagement perspective to investigate the antecedents of UPB (e.g., Chen et al. 2016; Umphress et al. 2010), thus giving rise to the concern about whether UPB actors would feel guilty. By introducing a moral cleansing mechanism about the outcome of UPB, we extend our understanding about UPB in that although it is conducted in the name of others' good, UPB actors do reflect on the immorality of their behaviors, and give rise to the feelings of guilt and subsequent compensating behaviors (e.g., prohibitive and promotive voice).

Second, we also contribute to the voice literature by examining the role of felt guilt in performing prohibitive and promotive voice, answering calls of research on affect and emotion in influencing voice behavior (Morrison 2011). Some studies have begun to pay attention to the role of emotions in soliciting voice behaviors. For instance, anger triggers voice while fear makes people silent (Kirrane et al. 2017). Although not empirically examined, Edwards et al. (2009) suggested that guilt could predict speaking up. Our research thus extends understandings about the effect of guilt in soliciting prohibitive and promotive voice by applying a moral cleansing perspective. By doing so, we enrich research on the antecedence of employees' voice from an emotion perspective.

Third, we also contribute to the moral identity literature by emphasizing the role of its symbolic dimension in smoothing the process of moral cleansing. Most studies that incorporated moral identity as a moderator roughly theorized the moderating effect of the unidimensional moral identity but used the internalization subscale in the measurement (e.g., Johnson and Umphress 2019; Skarlicki et al. 2016; Xu and Ma 2016). However, recent research shows that the roles of the two dimensions of moral identity may differ (e.g., Gotowiec and van Mastrigt 2019; Zhu et al. 2020). Thus, it is necessary to specify which dimension actually plays the role in a particular research framework. The current research thus helps clarify the moderating role of MIS in restoring a public moral self-image. After feeling guilt, people with high MIS are more likely to engage in observable compensating behaviors such as prohibitive and promotive voice to regain a public moral self-image.

\section{Practical Implications}

Although we found UPB actors were likely to feel guilty and subsequently engage in prohibitive and promotive voices, we never meant to encourage UPB in the workplace. Instead, we agree with the extant assertion that UPB causes harm to both external stakeholders and the organization in the long run (e.g., Wang et al. 2019a, b). Managers should certainly continue to train employees to avoid UPB, but in the meanwhile, as UPB widely exists in the workplace (Umphress and Bingham 2011), it is important for managers to realize what will happen to those UPB actors. By acknowledging that employees may react to their UPB with guilt, which is one kind of negative emotion caused by moral dissonance and rebuffed by people (Zhong and Liljenquist 2006), managers can help employees preview that they would experience guilt if they conduct UPB, thus discouraging employees from engaging in those behaviors in the first place.

Second, although guilt is usually regarded as a negative emotion, our research shows that it may bring benefiting outcomes, such as promotive and prohibitive voice, under certain circumstance. Managers should acknowledge this potential positive side of the emotion of guilt. In addition, they can create an open and friendly climate to encourage employees who feel guilty for the work or organization, for whatever reason, to compensate and cleanse by providing promotive and prohibitive voice.

Third, our research emphasized the importance of hiring employees high in moral identity. On one hand, as showed in our research, employees' MIS strengthened the relationship between felt guilt and two kinds of voice, as well as the indirect relationship between UPB acting and two kinds of voice via the mediation of felt guilt, we suggest that employees with higher MIS have a stronger desire to cleanse their past wrong deeds by engaging in compensating behaviors, even though they have to bear more personal risks. Moreover, although not illustrated in our hypothesized model, previous research showed that employees with higher internalized moral identity were less likely to conduct unethical behaviors (e.g., Bryant and Merritt 2019). Our results in Study 2 also showed that MII was negatively related to 
UPB $(r=-0.17, p<0.05)$. Therefore, hiring employees who value morality in their self-concept could benefit the organization in reducing unethical behaviors, including UPB.

\section{Limitations and Future Research Directions}

The contribution of our research should be qualified in light of its limitations. First, we adopted the perspective of the actors to investigate the outcome of UPB. Actually, there may be other perspectives and mechanisms to be explored in the future research. For example, from the perspective of the actors, UPB acting may cause positive emotions because unethical behavior brings short-term benefits and indicates a sense of autonomy and influence (Ruedy et al. 2013), and the pro-organization intention may strengthen this effect (Umphress et al. 2010), altogether giving rise to voice behaviors (Morrison 2011). From the perspective of the observers, UPB acting may cause a sense of moral disengagement or moral scrutiny. While from the perspective of the short-term beneficiary of UPB, such as the managers, UPB may cause a disruption to their moral image. We suggest investigating bystanders' reaction to UPB would be very meaningful for our understanding of the outcome of UPB.

Second, in Study 2, although we conducted a two-wave survey, we collected data from one single source. We attempted to address this common method variance (CMV) issue by collecting data of the predictor and criterion variables at two time points (Podsakoff et al. 2003). In addition, we conducted a scenario-based experiment in Study $1 \mathrm{~A}$ to test the causal relationships and tested the effect of UPB acting on felt guilt and subsequent actual (promotive) voice behavior in Study 1B. Future study can lessen the CMV issue by collecting data using multi-source and multi-wave approach.

Third, there might be other forms of behavioral outcomes of UPB acting, other than voice. Although we argue that voice serves to compensate both victims of UPB, as previously discussed, voice involves risk (Liang et al. 2012; Morrison 2011). Although the risk entailed in voice behavior largely helps to remove feelings of ethical dissonance (Nelissen and Zeelenberg 2009), it is quite likely that employees may choose other less risky behaviors to compensate, such as prosocial behavior, helping behavior, and organizational citizenship behavior. We encourage future research to explore other important outcomes of UPB.

Last but not least, it should be noted that except in Study 1A's scenario-based experiment, UPB and felt guilt only showed small to medium correlation in Studies $1 \mathrm{~B}$ and 2. Though our correlations are comparable to that in other studies (Mesdaghinia et al. 2019; Tang et al. 2020), we need to understand that there might be other emotional reactions of UPB, such as pride (Tang et al. 2020) and shame (Umphress and Bingham 2011), which may lead to different behavioral consequences. This could be a fruitful future research avenue.

\section{Conclusion}

Our research provides an empirical investigation of the consequence of UPB from the perspective of the focal actors and demonstrates a moral cleansing process after UPB conduction. Our findings across three studies support the positive relationship between UPB acting and prohibitive and promotive voice via felt guilt, and the moderating effect of MIS. Thus, we shed new light on the possible constructive consequence of UPB and to some extent give a second chance for the perpetrators to solve the moral dissonance and restore morality.

Acknowledgements We thank Dr. Huiwen Lian for her friendly review on an earlier version of the manuscript. We would like to thank Dr. Dawn R. Elm (Section editor) and two anonymous reviewers for their constructive comments on this paper.

Funding This research is supported by National Natural Science Foundation of China (Grant No. 71872005; 71872008).

\section{Compliance with Ethical Standards}

Conflict of interest The authors declare that they have no conflict of interest.

Ethical Approval At the time the data were collected in Studies 1A and 2 , the IRB is unavailable in our institution. Nonetheless, we complied with all guidelines for the ethical treatment of human participants, and with the 1964 Helsinki Declaration and its later amendments or comparable ethical standards. In addition, Study 1B was approved by the Internal Review Board at Peking University, with the Reference Code as \#2020-01.

Informed Consent Informed consent was obtained from all individual participants included in Studies 1A, 1B, and 2 of our research.

\section{References}

Aguinis, H., \& Bradley, K. J. (2014). Best practice recommendations for designing and implementing experimental vignette methodology studies. Organizational Research Methods, 17(4), 351-371.

Aiken, L. S., \& West, S. G. (1991). Multiple regression: Testing and interpreting interactions. Newbury Park, CA: Sage.

Amodio, D. M., Devine, P. G., \& Harmon-Jones, E. (2007). A dynamic model of guilt: Implications for motivation and self-regulation in the context of prejudice. Psychological Science, 18(6), 524-530.

Aquino, K., \& Reed, A., II. (2002). The self-importance of moral identity. Journal of Personality and Social Psychology, 83(6), 1423-1440.

Barkan, R., Ayal, S., Gino, F., \& Ariely, D. (2012). The pot calling the kettle black: Distancing response to ethical dissonance. Journal of Experimental Psychology: General, 141(4), 757-773. 
Barkan, R., Ayal, S., \& Ariely, D. (2015). Ethical dissonance, justifications, and moral behavior. Current Opinion in Psychology, 6(Dec), 157-161.

Bass, B. M. (1985). Leadership and performance beyond expectations. New York: Free Press.

Bastian, B., Jetten, J., \& Fasoli, F. (2011). Cleansing the soul by hurting the flesh: The guilt-reducing effect of pain. Psychological Science, 22(3), 334-335.

Bazerman, M. H., Tenbrunsel, A. E., \& Wade-Benzoni, K. A. (1998). Negotiating with yourself and losing: Making decisions with internal competing preferences. Academy of Management Review, 23(2), 225-241.

Bierbrauer, G. (1992). Reactions to violation of normative standards: A cross-cultural analysis of shame and guilt. International Journal of Psychology, 27(2), 181-193.

Blasi, A. (1993). The development of moral identity: Some implications for moral functioning. In G. Noam \& T. Wren (Eds.), The moral self (pp. 99-122). Cambridge, MA: MIT Press.

Bohns, V. K., \& Flynn, F. J. (2013). Guilt by design: Structuring organizations to elicit guilt as an affective reaction to failure. Organization Science, 24(4), 1157-1173.

Bonner, J. M., Greenbaum, R. L., \& Quade, M. J. (2017). Employee unethical behavior to shame as an indicator of self-image threat and exemplification as a form of self-image protection: The exacerbating role of supervisor bottom-line mentality. Journal of Applied Psychology, 102(8), 1203-1221.

Brislin, R. W. (1986). A culture general assimilator: Preparation for various types of sojourns. International Journal of Intercultural Relations, 10(2), 215-234.

Bryant, W., \& Merritt, S. M. (2019). Unethical pro-organizational behavior and positive leader-employee relationships. Journal of Business Ethics. https://doi.org/10.1007/s10551-019-04211-x.

Burris, E. R., Rockmann, K. W., \& Kimmons, Y. S. (2017). The value of voice to managers: Employee identification and the content of voice. Academy of Management Journal, 60(6), 2099-2125.

Caldwell, C., \& Canuto-Carranco, M. (2010). "Organizational terrorism" and moral choices-Exercising voice when the leader is the problem. Journal of Business Ethics, 97(1), 159-171.

Carlsmith, J. M., \& Gross, A. E. (1969). Some effects of guilt on compliance. Journal of Personality and Social Psychology, 11(11), 232-239.

Chen, M., Chen, C. C., \& Sheldon, O. J. (2016). Relaxing moral reasoning to win: How organizational identification relates to unethical pro-organizational behavior. Journal of Applied Psychology, 101(8), 1082-1096.

CNN.com. (2012). https://money.cnn.com/2012/08/07/news/compa nies/pfizer-bribery-charges/.

Cohen, T. R., Wolf, S. T., Panter, A. T., \& Insko, C. A. (2011). Introducing the gasp scale: A new measure of guilt and shame proneness. Journal of Personality and Social Psychology, 100(5), 947-966.

Cryder, C. E., Springer, S., \& Morewedge, C. K. (2012). Guilty feelings, targeted actions. Personality and Social Psychology Bulletin, 38(5), 607-618.

Matherne, C. F., III., \& Litchfield, S. R. (2012). Investigating the relationship between affective commitment and unethical proorganizational behaviors: The role of moral identity. Journal of Leadership, Accountability and Ethics, 9(5), 35-46.

Detert, J. R., \& Burris, E. R. (2007). Leadership behavior and employee voice: Is the door really open? Academy of Management Journal, 50(4), 869-884.

Detert, J. R., Burris, E. R., Harrison, D. A., \& Martin, S. R. (2013). Voice flows to and around leaders understanding when units are helped or hurt by employee voice. Administrative Science Quarterly, 58(4), 624-668.
Dunn, P., Farrar, J., \& Hausserman, C. (2018). The influence of guilt cognitions on taxpayers' voluntary disclosures. Journal of Business Ethics, 148(3), 689-701.

Dutton, J. E., \& Ashford, S. J. (1993). Selling issues to top management. Academy of Management Review, 18(3), 397-428.

Edwards, M. S., Ashkanasy, N. M., \& Gardner, J. (2009). Deciding to speak up or to remain silent following observed wrongdoing: The role of discrete emotions and climate of silence. In J. Greenberg \& M. S. Edwards (Eds.), Voice and silence in organizations (pp. 83-109). Bingley: Emerald.

Festinger, L. (1957). A theory of cognitive dissonance. Evanston, IL: Row, Peterson.

Fuller, J. B., Marler, L. E., \& Hester, K. (2006). Promoting felt responsibility for constructive change and proactive behavior: Exploring aspects of an elaborated model of work design. Journal of Organizational Behavior, 27, 1089-1120.

Ghorbani, M., Liao, Y., Çayköylü, S., \& Chand, M. (2013). Guilt, shame, and reparative behavior: The effect of psychological proximity. Journal of Business Ethics, 114(2), 311-323.

Glucklich, A. (2001). Sacred pain: Hurting the body for the sake of the soul. New York: Oxford University Press.

Gollwitzer, M., \& Melzer, A. (2012). Macbeth and the joystick: Evidence for moral cleansing after playing a violent video game. Journal of Experimental Social Psychology, 48(6), 1356-1360.

Gotowiec, S., \& van Mastrigt, S. (2019). Having versus doing: The roles of moral identity internalization and symbolization for prosocial behaviors. The Journal of Social Psychology, 159(1), 75-91.

Graham, K. A., Resick, C. J., Margolis, J. A., Shao, P., Hargis, M. B., \& Kiker, J. D. (2020). Egoistic norms, organizational identification, and the perceived ethicality of unethical pro-organizational behavior: A moral maturation perspective. Human Relations, 73(9), 1249-1277.

Gurchiek, K. (2006). US workers unlikely to report office misconduct. HR Magazine, 51, 38.

Harth, N. S., Leach, C. W., \& Kessler, T. (2013). Guilt, anger, and pride about in-group environmental behaviour: Different emotions predict distinct intentions. Journal of Environmental Psychology, 34, 18-26.

Hau, K. T., \& Marsh, H. W. (2004). The use of item parcels in structural equation modelling: Non-normal data and small sample sizes. British Journal of Mathematical and Statistical Psychology, 57(2), 327-351.

Hayes, A. F. (2013). Introduction to mediation, moderation, and conditional process analysis: A regression-based approach. Journal of Educational Measurement, 51(3), 335-337.

Johnson, H. H., \& Umphress, E. E. (2019). To help my supervisor: Identification, moral identity, and unethical pro-supervisor behavior. Journal of Business Ethics, 159(2), 519-534.

Jordan, J., Mullen, E., \& Murnighan, J. K. (2011). Striving for the moral self: The effects of recalling past moral actions on future moral behavior. Personality and Social Psychology Bulletin, 37(5), 701-713.

Kakkar, H., Tangirala, S., Srivastava, N. K., \& Kamdar, D. (2016). The dispositional antecedents of promotive and prohibitive voice. Journal of Applied Psychology, 101(9), 1342-1351.

Kirrane, M., O'Shea, D., Buckley, F., Grazi, A., \& Prout, J. (2017). Investigating the role of discrete emotions in silence versus speaking up. Journal of Occupational and Organizational Psychology, 90(3), 354-378

Lavelle, J. J., Harris, C. M., Rupp, D. E., Herda, D. N., Young, R. F., Hargrove, M. B., et al. (2018). Multifoci effects of injustice on counterproductive work behaviors and the moderating roles of symbolization and victim sensitivity. Journal of Organizational Behavior, 39(8), 1022-1039. 
Lee, A., Schwarz, G., Newman, A., \& Legood, A. (2019). Investigating when and why psychological entitlement predicts unethical pro-organizational behavior. Journal of Business Ethics, 154(1), $109-126$.

Liang, J., Farh, C. I. C., \& Farh, J. L. (2012). Psychological antecedents of promotive and prohibitive voice: A two-wave examination. Academy of Management Journal, 55(1), 71-92.

Lin, S. H., \& Johnson, R. E. (2015). A suggestion to improve a day keeps your depletion away: Examining promotive and prohibitive voice behaviors within a regulatory focus and ego depletion framework. Journal of Applied Psychology, 100(5), 1381-1397.

Linda, T., Stefan, S., \& Gregorio, L. R. (2016). Empathy, guilt proneness, and gender: Relative contributions to prosocial behavior. Europe's Journal of Psychology, 12(2), 260-270.

Liu, W., Zhu, R., \& Yang, Y. (2010). I warn you because I like you: Voice behavior, employee identifications, and transformational leadership. Leadership Quarterly, 21(1), 189-202.

May, D. R., Chang, Y. K., \& Shao, R. (2015). Does ethical membership matter? Moral identification and its organizational implications. Journal of Applied Psychology, 100(3), 681-694.

Mazar, N., Amir, O., \& Ariely, D. (2008). The dishonesty of honest people: A theory of self-concept maintenance. Journal of Marketing Research, 45(6), 633-644.

Mesdaghinia, S., Rawat, A., \& Nadavulakere, S. (2019). Why moral followers quit: Examining the role of leader bottom-line mentality and unethical pro-leader behavior. Journal of Business Ethics, 159(2), 491-505.

Monin, B., \& Jordan, A. H. (2009). The dynamic moral self: A social psychological perspective. In Personality, identity, and character: Explorations in moral psychology (pp 341-354). Cambridge: Cambridge University Press

Morrison, E. W. (2011). Employee voice behavior: Integration and directions for future research. Academy of Management Annals, 5(1), 373-412.

Morrison, E. W., \& Milliken, F. J. (2000). Organizational silence: A barrier to change and development in a pluralistic world. Academy of Management Review, 25(4), 706-725.

Nelissen, R. M., \& Zeelenberg, M. (2009). When guilt evokes selfpunishment: Evidence for the existence of a dobby effect. Emotion, 9(1), 118-122.

Ormiston, M. E., \& Wong, E. M. (2013). License to ill: The effects of corporate social responsibility and CEO moral identity on corporate social irresponsibility. Personnel Psychology, 66(4), 861-893.

Podsakoff, P. M., Mackenzie, L., \& Podsakoff J. (2003). Common method biases in behavioral research: A critical review of the literature and recommendation remedies. Journal of Applied Psychology, 88(5), 879-903.

Podsakoff, P. M., Mackenzie, S. B., Moorman, R. H., \& Fetter, R. (1990). Transformational leader behaviors and their effects on followers' trust in leader, satisfaction, and organizational citizenship behaviors. Leadership Quarterly, 1(2), 107-142.

Preacher, K. J., \& Hayes, A. F. (2008). Contemporary approaches to assessing mediation in communication research. Thousand Oaks, CA: Sage Publications, Inc.

Reed, A., II., \& Aquino, K. F. (2003). Moral identity and the expanding circle of moral regard toward out-groups. Journal of Personality and Social Psychology, 84(6), 1270-1286.

Ruedy, N. E., Moore, C., Gino, F., \& Schweitzer, M. E. (2013). The cheater's high: The unexpected affective benefits of unethical behavior. Journal of Personality and Social Psychology, 105(4), 531-548.

Sachdeva, S., Iliev, R., \& Medin, D. L. (2009). Sinning saints and saintly sinners. The paradox of moral self-regulation. Psychological Science, 20(4), 523-528.
Shalvi, S., Gino, F., Barkan, R., \& Ayal, S. (2015). Self-serving justifications: Doing wrong and feeling moral. Current Directions in Psychological Science, 24(2), 125-130.

Skarlicki, D. P., Van Jaarsveld, D. D., \& Walker, D. D. (2008). Getting even for customer mistreatment: The role of moral identity in the relationship between customer interpersonal injustice and employee sabotage. Journal of Applied Psychology, 93(6), 1335-1347.

Skarlicki, D. P., van Jaarsveld, D. D., Shao, R., Song, Y. H., \& Wang, M. (2016). Extending the multifoci perspective: The role of supervisor justice and moral identity in the relationship between customer justice and customer-directed sabotage. Journal of Applied Psychology, 101(1), 108-121.

Starzyk, A., Sonnentag, S., \& Albrecht, A. G. (2018). The affective relevance of suggestion-focused and problem-focused voice: A diary study on voice in meetings. Journal of Occupational and Organizational Psychology, 91(2), 340-361.

Steenhaut, S., \& Kenhove, P. V. (2006). An empirical investigation of the relationships among a consumer's personal values, ethical ideology and ethical beliefs. Journal of Business Ethics, 64(2), 137-155.

Tang, P. M., Yam, K. C., \& Koopman, J. (2020). Feeling proud but guilty? Unpacking the paradoxical nature of unethical pro-organizational behavior. Organizational Behavior and Human Decision Processes, 160, 68-86.

Tangirala, S., \& Ramanujam, R. (2010). Employee silence on critical work issues: The cross-level effects of procedural justice climate. Personnel Psychology, 61(1), 37-68.

Tangney, J. P., Mashek, D., \& Stuewig, J. (2007). Working at the social-clinical-community-criminology interface: The GMU inmate study. Journal of Social and Clinical Psychology, 26(1), $1-21$.

Tenbrunsel, A. E., Diekmann, K. A., Wade-Benzoni, K. A., \& Bazerman, M. H. (2010). The ethical mirage: A temporal explanation as to why we are not as ethical as we think we are. Research in Organizational Behavior, 30, 153-173.

ThePaper.cn. (2019). https://www.thepaper.cn/newsDetail_forwa rd 3584917 .

Tom, S. M., Fox, C. R., Trepel, C., \& Poldrack, R. A. (2007). The neural basis of loss aversion in decision-making under risk. Science, 315(5811), 515-518.

Tracy, J. L., \& Robins, R. W. (2006). Appraisal antecedents of shame and guilt: Support for a theoretical model. Personality and Social Psychology Bulletin, 32(10), 1339-1351.

Umphress, E. E., \& Bingham, J. B. (2011). When employees do bad things for good reasons: Examining unethical pro-organizational behaviors. Organization Science, 22(3), 621-640.

Umphress, E. E., Bingham, J. B., \& Mitchell, M. S. (2010). Unethical behavior in the name of the company: The moderating effect of organizational identification and positive reciprocity beliefs on unethical pro-organizational behavior. Journal of Applied Psychology, 95(4), 769-780.

Van Dyne, L., \& LePine, J. A. (1998). Helping and voice extra-role behaviors: Evidence of construct and predictive validity. The Academy of Management Journal, 41(1), 108-119.

Vlachos, P. A., Panagopoulos, N. G., \& Rapp, A. A. (2014). Employee judgments of and behaviors toward corporate social responsibility: A multi-study investigation of direct, cascading, and moderating effects. Journal of Organizational Behavior, 35(7), 990-1017.

Wang, T., Long, L., Zhang, Y., \& He, W. (2019a). A social exchange perspective of employee-organization relationships and employee unethical pro-organizational behavior: the moderating role of individual moral identity. Journal of Business Ethics, 159(2), 473-489.

Wang, J., Zhang, Z., \& Jia, M. (2019b). Echoes of corporate social responsibility: How and when does CSR influence employees' 
promotive and prohibitive voices? Journal of Business Ethics, 159(2), 1-17.

Winterich, K. P., Aquino, K., Mittal, V., \& Swartz, R. (2013). When moral identity symbolization motivates prosocial behavior: The role of recognition and moral identity internalization. Journal of Applied Psychology, 98(5), 759-770.

Xu, Z. X., \& Ma, H. K. (2016). How can a deontological decision lead to moral behavior? The moderating role of moral identity. Journal of Business Ethics, 137(3), 537-549.

Yang, C., Nay, S., \& Hoyle, R. H. (2010). Three approaches to using lengthy ordinal scales in structural equation models: Parceling, latent scoring, and shortening scales. Applied Psychological Measurement, 34(2), 122-142.

Yukl, G. A. (1989). Leadership in organizations (2nd ed.). Englewood Cliffs, NJ: Prentice-Hall.
Zhong, C. B., \& Liljenquist, K. (2006). Washing away your sins: Threatened morality and physical cleansing. Science, 313(5792), 1451-1452.

Zhu, L. L., Restubog, S. L. D., Leavitt, K., Zhou, L., \& Wang, M. (2020). Lead the horse to water, but don't make him drink: The effects of moral identity symbolization on coworker behavior depend on perceptions of proselytization. Organizational Behavior and Human Decision Processes, 156, 53-68.

Publisher's Note Springer Nature remains neutral with regard to jurisdictional claims in published maps and institutional affiliations. 